Portland State University

PDXScholar

\title{
Survey Deficiencies as Quality Indicators in Oregon Assisted Living Communities
}

\author{
Ozcan Tunalilar \\ Portland State University, tozcan@pdx.edu \\ Sunny C. Lin \\ Portland State University, sunlin@pdx.edu \\ Paula C. Carder \\ Portland State University, carderp@pdx.edu
}

Follow this and additional works at: https://pdxscholar.library.pdx.edu/aging_pub

Part of the Gerontology Commons, Inequality and Stratification Commons, and the Medicine and Health Commons

Let us know how access to this document benefits you.

\section{Citation Details}

Tunalilar, Ozcan; Lin, Sunny C.; and Carder, Paula C., "Survey Deficiencies as Quality Indicators in Oregon Assisted Living Communities" (2021). Institute on Aging Publications. 101.

https://pdxscholar.library.pdx.edu/aging_pub/101

This Pre-Print is brought to you for free and open access. It has been accepted for inclusion in Institute on Aging Publications by an authorized administrator of PDXScholar. Please contact us if we can make this document more accessible: pdxscholar@pdx.edu. 
Title: Survey Deficiencies as Quality Indicators in Oregon Assisted Living Communities 


\begin{abstract}

\section{Background and Objectives}

License inspection data have commonly been used as a quality measure for nursing homes but has not yet been used to assess the quality of assisted living/residential care (AL/RC) communities. We use deficiency citations to examine the quality of AL/RC communities in Oregon and identify structural and environmental characteristics associated with inspection results.

\section{Research Design and Methods}

Using data from 526 licensed $A L / R C$ communities in Oregon that received a license inspection visit between 2008 and 2016, we examined the prevalence of deficiency citations by type and year. We then estimated regression models to identify structural and environmental characteristics associated with the number of deficiency citations.

\section{Results}

Most (64\%) inspections resulted in at least one deficiency citation. The most common citations were medications and treatments (57\%), change of condition and monitoring (48\%), and resident health services (45\%). Several structural characteristics were associated with higher odds of receiving one or more deficiency citations, including: larger size, memory care designation, rural location, longer administrative tenure, and for-profit status. Environmental characteristics associated with higher odds of receiving one or more deficiency citations included: rural location, low unemployment, and market concentration. The number and likelihood of a given community receiving a deficiency citation decreased over time.
\end{abstract}

\title{
Discussion and Implications
}


As measured by number of deficiency citations, AL/RC quality is associated with higher risk of exposure, longer institutional knowledge, greater resource availability, and market pressure. These results demonstrate that license inspection data are a viable option for assessing the quality of AL/RC communities.

Keywords: long-term care, quality of care, deficiency citations, license inspections 


\section{Background and Objectives}

Older adults who have chronic health conditions and physical or cognitive impairments often rely on a variety of long-term services and supports (LTSS), including assisted living and residential care (AL/RC) communities. In 2016, there were over $800,000 \mathrm{AL} / \mathrm{RC}$ residents, and over half were aged 85 of older (52 percent), received assistance with bathing (64 percent) and walking/locomotion (57 percent), nearly half received help with dressing (48 percent), and 42 percent had a diagnosis of Alzheimer's disease or a related dementia (Harris-Kojetin et al., 2019). The number of AL/RC residents with cognitive impairment is estimated at 7 out of 10 (Zimmerman et al., 2014). These statistics indicate that significant numbers of this population are vulnerable due to physical frailty and cognitive impairment.

The quality of LTSS provided to older adults and persons with physical and cognitive impairments has long been a topic of concern among researchers and policymakers (Institute of Medicine, 2001; Kane, 2001; Mueller, 2002). Within the nursing facility sector, survey deficiencies have commonly been used as a quality measure (Castle, 2010; Castle \& Ferguson, 2010; Li et al., 2015). Like nursing homes, $\mathrm{AL} / \mathrm{RC}$ s are licensed and subject to regulatory enforcement and oversight. While the need to assess quality in the AL/RC setting has been described (Hawes \& Phillips, 2007; Zimmerman et al., 2005), few studies have done so using survey deficiencies, possibly because states are responsible for the licensing, enforcement, and oversight of these settings (Smith et al., 2021). Fortunately, existing state administrative records, such as deficiencies and consumer complaints, can be used to understand quality in AL/RCs. To date, only two studies have used such data. One found that specialty 
licenses (e.g., mental health, dementia care) and region were associated with the number of deficiencies received by AL/RC in Florida (June et al., 2019). An Arizonabased study of complaint records found that facility-level risk factors were associated with substantiated allegations of mistreatment, including larger size and national corporate ownership (associated with for-profit status), but not resident-level risk factors (Phillips \& Guo, 2011).

Rationale

The gap in knowledge about AL/RC deficiencies and consumer complaints, and their relationship to resident health outcomes, has serious ramifications for the health, safety, and overall well-being of thousands of older adult residents in the U.S. The U.S. Government Accountability Office (GAO, 2018) reported that states lack methods for overseeing and reporting neglect, abuse, exploitation, and other critical incidents in these settings.

Our study draws on resource dependency theory, which posits that organizational performance is dependent on the ability of an organization to navigate its external environment (Pfeffer \& Salancik, 2003). Specifically, resource dependency theory suggests that certain AL/RC characteristics may be associated with $A L / R C$ quality if these characteristics impact the ability of organizations to attract, attain, and manage vital resources in its environment. For example, rural AL/RC may have lower quality if they have difficulty attracting and retaining sufficient staffing levels or specific categories of staff (e.g., licensed nurse, administrator).

Study Objectives 
The overall objective of this research is to advance our understanding of the relationship between survey deficiencies and quality in AL/RC settings. To do this, we analyze multiple years of administrative records to examine whether deficiencies were associated with certain AL/RC characteristics. Specifically, we examine structural characteristics that relate to an AL/RC's internal resources and capabilities, and environmental characteristics that capture an AL/RC's external resources and pressures.

Our contribution to the literature is threefold. First, we extend previous work on the use of deficiency data and AL/RC quality in Florida (June et al., 2019) and Arizona (Phillips and Guo, 2011) to Oregon, a state recognized as a pioneer in the AL/RC model of LTSS (Eckert et al., 2009; Frytak et al., 2001). Second, we provide proof of concept of how important and novel system and process measures can be used to assess AL/RC quality. Finally, we move beyond cross-sectional analysis by using longitudinal data to examine the incidence of survey deficiencies over time. In addition, we include as a variable multiple enforcement visits rather than only the most recent visit as was done by prior authors (June et al., 2019).

\section{Research Design and Methods}

\section{Study Design}

This study employed panel data to understand correlates of deficiency citations. The analytic sample included $526 \mathrm{AL} / \mathrm{RC}$ s that received at least one licensing visit between 2008 and 2016. We examined whether the quality of an AL/RC, as measured by the number of deficiency citations, varies with key internal and environmental factors (e.g. ownership, size, urban/rural location) that may enhance or inhibit the ability of an 
$\mathrm{AL} / \mathrm{RC}$ to achieve and maintain high quality services. We then used resource dependency theory to explain why these characteristics are associated with performance, and make policy recommendations to target those organizations that may need additional support in achieving high quality care.

\section{Data Sources}

We received $A L / R C$ inspection ("survey") results conducted by the Oregon Department of Human Services (ODHS), which licenses two setting types, assisted living and residential care communities, either of which might receive ODHS approval to be designated as "memory care" (MC) communities. State surveyors conduct unannounced inspection surveys at least every 24 months. The state conducts different types of surveys during the operating cycle of a facility (e.g., initial licensure, re-license, in response to complaints, and revisits and follow-up). Each rule violation (hereafter, deficiency citation) is recorded as a separate incident in the survey team's report alongside the deficiency type.

Although we received data from all visits, we use data for visits that occurred between January 2008 and December 2016 because this was a stable period in terms of regulatory action. Specifically, sweeping changes occurred in 2007 and again in 2018 when an omnibus quality of care bill (House Bill 3359) was adopted. During the study period, there were 1,826 initial or re-licensing visits to $526 \mathrm{AL} / \mathrm{RC}$ communities. Seven AL/RC were excluded because they were open only briefly or opened in late 2016 and did not receive any visits. Out of $526 \mathrm{AL} / \mathrm{RCs}, 430$ (82 percent) had opened prior to the study period (before 2008) with a median operating time of 8.7 years prior to 2008 . 
Data on the AL/RC environment comes from the Area Health Resource File (AHRF) and the US Bureau of Labor Statistics (BLS). Except for the unemployment rate, all environmental characteristics were pulled from the AHRF for all available study years and assigned based on the AL/RC's county. Since some variables from the US census are not collected annually, missing information was carried forward from previous years' data. Annual data on county unemployment rate was collected from the BLS.

Variables

$A L / R C$ organizational characteristics include the number of years the $A L / R C$ was open at time of the visit, size (in number of beds), administrator tenure (in years), market share, license type, whether the AL/RC had a contract to serve Medicaid residents, and non-profit status. We also included survey year as a control variable. Unless otherwise noted, variables were measured for each year.

Number of years in operation. We calculated the number of years that each AL/RC was open as of the last inspection date by subtracting the year of the visit by the year the AL/RC opened.

Size. We used licensed capacity to create a 5-category measure $(0-24,25-49,50-74$, 75-99, and 100 and more) as a measure of AL/RC size.

Administrator tenure. We measured this variable by subtracting each administrator's job start date from the survey visit date. It was top-coded at 8 years due to measurement issues for a subset of AL/RC (115 out 1,826 cases) as ODHS records do not go back before 2000 for all facilities. 
Market share. Market share was calculated as the number of AL/RC beds divided by the total number of AL/RCs beds in the county multiplied by 100 to achieve a percentage point scale from $0-100$. For ease of interpretation, in our models we operationalized this variable as the highest quartile (17-100\%) versus the bottom 3 quartiles $(0-17 \%)$.

License type. As discussed above, Oregon uses two license categories (assisted living and residential care). In addition to this base license, a community can receive endorsement to provide Alzheimer's care. Some communities use all their available beds for this purpose while others combine regular $A L / R C$ beds with $M C$ units (e.g., as a wing or floor). Using licensing information, we created a 4-category measure of community type $(0=\mathrm{AL}$ (non-MC); 1 = RC (non-MC); 2 = standalone MC; and $3=$ $\mathrm{mixed} /$ combined).

Medicaid contract. This is a binary indicator for whether the AL/RC has a contract to serve Medicaid beneficiaries and get reimbursed for these services.

Non-profit status. We retrieved for-profit/non-profit information about the AL/RC owners from the Oregon Secretary of State website. We assigned all but non-profit corporations as for-profit companies (e.g., business corporations, limited liability companies, and limited and general partnerships).

The environment variables that we examined in our analysis examine whether the AL/RC is located in a county with the following characteristics: rural status ( 0 =metropolitan, 1=rural, 2=micropolitan), the number of certified skilled nursing facility (SNF) beds, share of older adults in the population, percent persons in poverty, percent of persons unemployed, percent Medicare population also eligible for Medicaid (dual 
eligible), and a proxy measure of market competition. Unless otherwise noted, variables were measured for each year. Data on older adult population, poverty, unemployment, and dual eligibility was only available for 2010-2016. Therefore, in our models, we assumed that 2008-2009 data for the variable were the same as 2010 . To test how sensitive our models were to these assumptions, we ran sensitivity analyses excluding 2008-2009. As results were not sensitive to this exclusion, they are not shown here (see Supplemental Materials).

Rural. We used 2018 Core Based Statistical Area (CBSA) codes from the Area Health Resource File to determine whether the AL/RC county was located in an metropolitan (urban area with a population of 50,000 or more), micropolitan (urban area with a population of $10,000-50,000$ ), or rural area (all other areas).

Number of Certified SNF beds. We used data from the Nursing Home Compare public use files to determine the number of total certified beds in skilled nursing facilities in the county.

Percent older adult population. We use census data from the Area Health Resource File to determine the percent of county population ages 65 or higher. For ease of interpretation, in our models we operationalized this variable as the highest quartile (18$34 \%)$ versus the bottom 3 quartiles (10-18\%).

Percent poverty. We use census data from the Area Health Resource File to determine the percent of county population that were living in poverty. For ease of interpretation, in our models we operationalized this variable as the highest quartile (19-39\%) versus the bottom 3 quartiles (9-19\%). 
Percent unemployment. We use census data from the Area Health Resource File to determine the percent of county population that were unemployed. For ease of interpretation, in our models we operationalized this variable as the highest quartile (10$18 \%)$ versus the bottom 3 quartiles (4-10\%).

Percent Medicare population eligible for Medicaid. We use Medicare data from the Area Health Resource File to determine the percent of Medicare beneficiaries in the county that were dually eligible for Medicaid. For ease of interpretation, in our models we operationalized this variable as the highest quartile (23-29\%) versus the bottom 3 quartiles $(9-23 \%)$.

Market Competition. We calculated market competition using the HerfindahlHirschman Index $(\mathrm{HHI})$ of residences' beds in the county. $\mathrm{HHI}$ allows us to characterize competition within a county on a scale of perfect competition $(\mathrm{HHI}=0)$ to monopoly $(\mathrm{HHI}=1)$. For ease of interpretation, we characterized market competition into categories by using quartiles as follows: most competitive (0.03 - 0.05), moderately concentrated ( $2^{\text {nd }}$ and $3^{\text {rd }}$ quartiles of $\mathrm{HHI} ; 0.06-0.22$ ), and highly concentrated including monopolistic (0.22-1.00).

Statistical Analysis

To describe the analytic sample, we calculated means (continuous variables) and percentages (categorical variables) of our AL/RC organizational and environmental characteristics. We then examined the distribution of the number of citations across years and the reasons behind deficiency citations, and compared inter-residence variation with between-residence variation to understand whether the quality of a AL/RC is a long-term characteristic of these communities or more transient over time. 
To understand how AL/RC organizational and environmental characteristics are associated with probability of receiving a citation and number of citations, we ran two models. First, we estimated multilevel mixed-effects logistic regression models for the likelihood of having at least one deficiency as the outcome, and organizational and environmental characteristics as the covariates. Then, we estimated multilevel mixedeffects Poisson regression models to analyze the relationship between the total number of deficiency citations that a residence received during each visit as the outcome, and organizational and environmental characteristics as the covariates. To account for repeated measures from $A L / R C$ and the resulting clustering, in both sets of models, we included community-level random intercepts (Rabe-Hesketh and Skrondal, 2012). All analyses were conducted using Stata (version 16, Stata Corp.).

To test the sensitivity of our models to our treatment of missing census data from 2008-2009, we re-ran our models using only 2010-2016 data. To test the sensitivity of our model to overdispersion, we re-ran our Poisson model using a mixed-effects negative binomial regression model. Finally, to test the sensitivity of our model to correlation of environmental variables, we ran our models excluding number of SNF certified beds in the county, which was moderately correlated with percent of Medicare beneficiaries eligible for Medicaid (correlation coefficient 0.68 ) and market competition (correlation coefficient -0.73). The extent to which the main findings are sensitive to these changes is discussed in the Results section.

\section{Results}

Survey Visits and Deficiency Citations 
Data on 1,826 inspections for $526 \mathrm{AL} / \mathrm{RC}$ were included in our analysis.

Description of survey deficiencies per visit over time are presented in Table 1. Most visits, or 79 percent, received at least one deficiency citation, and the average number of deficiencies per visit was $5.2(S D=5.0)$. During the nine-year study window, the average number of visits per $\mathrm{AL} / \mathrm{RC}$ was 3.5 , ranging from 1 to 5 (not shown in table). Out of $526 \mathrm{AL} / \mathrm{RC}$ included in the study, most received four (58 percent; $\mathrm{n}=305$ ) or five (7 percent; $n=37$ ) visits; 46 (9 percent) received only one visit, 39 (7 percent) received two visits, and 99 (19 percent) received three visits.

\section{[Table 1 About Here]}

We next examine the prevalence of a subset of deficiency citations for licensing visits that remained consistent during this period. These citations were coded as 0 if none was received and 1 if at least one was received in the subcategory. Figure 1 presents the prevalence of these specific citations, in descending order. Most licensing visits $(69 \%)$ resulted in at least one citation out of three most common citations:

medications and treatments (57\%), change of condition and monitoring (48\%), or resident health services $(45 \%)$.

\section{[Figure 1 About Here]}

\section{Community Characteristics}

Characteristics of AL/RC inspected during survey visits are presented in Table 2. Of interest, 21.5 percent of $\mathrm{AL} / \mathrm{RC}$ were designated for MC. Most AL/RC (77.9\%) had a contract to provide services to Medicaid residents and receive reimbursement. A small share $(10.6 \%)$ were non-profit. Most $(77.6 \%)$ were serving metropolitan communities. In bivariate analyses, those that received no deficiency citations were significantly different 
from those that received at least one deficiency in terms of size, license type, Medicaid contract, administrator tenure, non-profit status, market share, and county unemployment (see Table 2).

\section{[Table 2 About Here]}

\section{Multivariable Analysis}

To estimate an unconditional intraclass correlation (ICC), we estimated an empty (without any covariates) multilevel mixed-effects logistic regression model for the likelihood of receiving at least one deficiency during a visit. The estimated ICC was .26, indicating that a quarter of the variance ( 26 percent) in the likelihood of receiving at least one deficiency citation was due to the between-facility variability. As such, AL/RCs differed in their likelihood of receiving at least one deficiency citation more over time (within-facility variance) than compared to other AL/RCs (between-facility variance).

We next examined the correlates of receiving at least one deficiency from a licensure visit (Table 3, Model 1). The likelihood of receiving at least one citation decreased over time. Larger $\mathrm{AL} / \mathrm{RC}, \mathrm{MC}$ designated, and $\mathrm{AL} / \mathrm{RC}$ located in rural areas had a higher likelihood of receiving at least one deficiency citation compared to their counterparts. AL/RC managed by administrators with longer tenure, as well as nonprofit $A L / R C$ and those located in counties with high unemployment had a lower likelihood of receiving at least one deficiency citation.

[Table 3 About Here]

Then, we examined the correlates of number of deficiency citations received during licensure visits (Table 3, Model 2). The average number of deficiency citations received significantly decreased over time. Larger $A L / R C, M C$ designated, rural $A L / R C$, 
and $A L / R C$ in highly concentrated $A L / R C$ markets had a higher expected number of deficiency citations compared to smaller AL/RC, those with AL base license only, metropolitan and micropolitan AL/RC, and AL/RC located in competitive markets, respectively. $A L / R C$ with longer administrative tenure, non-profit $A L / R C$, and $A L / R C$ in counties with high unemployment had a lower expected number of deficiency citations.

To illustrate the significant effects of covariates on deficiency citations, we calculated the estimated number of citations using coefficients from the full mixedeffects Poisson model, holding all other covariates at their means. For instance, AL/RC with a licensed capacity of $6-24$ beds had an expected 3.7 citations compared to 8.8 for AL/RC with $100+$ beds. AL had an expected 4.5 citations on average compared to 5.8 for $\mathrm{RC}, 6.0$ for $\mathrm{MC}$, and 6.5 for $\mathrm{AL} / \mathrm{RC}$ s that have a mixed license. $\mathrm{AL} / \mathrm{RC}$ with an administrator of less than 1 year had an expected 5.6 citations compared to 4.5 citations for $A L / R C$ with an administrator of more than 8 years. For-profit $A L / R C$ had an expected 5.5 citations compared to 3.3 citations for non-profit AL/RC. Rural AL/RC had an expected 9.4 citations, micropolitan AL/RC had an expected 4.8 deficiency citations, and metropolitan AL/RC had an expected 5.2 deficiency citations. Finally, AL/RC in the most competitive and moderately concentrated counties had an expected 4.4 and 5.2 citations, respectively, and AL/RC located in the most highly concentrated counties had an expected 6.3 citations.

Sensitivity Analysis

Results from sensitivity analyses that re-ran our models using only 2010-2016 data suggests that our results were not sensitive to the way we imputed missing data from 2008-2009 (Supplemental Table 1). Similarly, our main results were held in the 
sensitivity analysis that used a mixed-effects negative binomial regression model, suggesting that our results were not impacted by overdispersion (Supplemental Table 2). Effect sizes and confidence intervals were similar with two small differences. In the mixed-effects negative binomial model accepting Medicaid was statistically significantly associated with more deficiency citations (IRR: $1.23,95 \% \mathrm{Cl}: 1.08,1.41$ compared to IRR: $1.12,95 \% \mathrm{Cl}: 0.95,1.32$ in the mixed-effects Poisson model) and AL/RC located in moderately concentrated markets had significantly more deficiency citations (IRR: 1.25, $95 \% \mathrm{Cl}: 1.07,1.45$ compared to IRR: $1.17,95 \% \mathrm{Cl}: 0.99,1.40$ in the mixed-effects Poisson model). Finally, results from our sensitivity analyses that excluded the number of SNF certified beds (which was moderately correlated with percent of Medicare beneficiaries dually eligible for Medicaid, and market competition) suggest that collinearity did not substantially alter our main results (Supplemental Table 3).

\section{Discussion and Implications}

In this study, we examined organizational and environmental factors associated with survey deficiency citations in AL/RC communities licensed in Oregon. To our knowledge, this study is the first to use longitudinal data to examine regulatory deficiencies in AL/RC communities. Information about state approaches to regulatory enforcement and consumer protections in these settings is lacking, as indicated by a recent U.S. GAO Report (2019). The current study provides a state-level example that other researchers can model.

Several findings are comparable to research on nursing home deficiency citations. Specifically, as with our findings, smaller facility size and non-profit status (Castle et al., 2010; Mullan and Harrington, 2001) as well as longer nursing home 
administrator tenure (Castle, 2001) are associated with fewer nursing home citations. Unlike nursing home research (Castle et al., 2010), presence of a Medicaid contract in Oregon AL/RC was not significantly associated with presence or the number of deficiency citations. However, the presence of a Medicaid contract does not mean that these AL/RC have any, or many, current Medicaid beneficiaries. For example, a 2018 survey of $524 \mathrm{AL} / \mathrm{RC}$ in Oregon found that while $79 \%$ reported having a Medicaid contract, only $42 \%$ of $A L / R C$ residents were current Medicaid beneficiaries (Carder et al., 2018).

Our finding that deficiency ratings are not stable within $A L / R C$ over time suggests that deficiency citations may not be stable or long-term indicators of quality at a particular AL/RC, but rather serve as a snapshot. In other words, there may be no lowquality facilities, but only facilities that are low-quality at a certain time, at least when measured using this indicator. This underscores the importance of regular updates to consumer-facing websites that include information about survey visit results such as deficiencies.

Our study suggests several general mechanisms associated with regulatory deficiencies, including risk of exposure, institutional knowledge, resource availability, and market pressure. We briefly discuss each mechanism below.

Exposure. The risk that an AL/RC will be exposed to a regulatory deficiency may be associated with organizational characteristics such as larger size, license type, and resident profile. Having more residents (e.g., larger facility size) may increase the risk of adverse events captured in deficiency citations, or the regulatory gaze might be higher in larger communities, as survey teams spend more time and make more repeat visits 
to these communities. MC communities may also be subject to greater risk given the considerably higher acuity among MC residents. As in other states (Carder, 2017), MC in Oregon must meet the $\mathrm{AL} / \mathrm{RC}$ requirements, in addition to other regulatory requirements that could increase the odds of receiving a deficiency. Specifically, MC must have building design features (e.g., controlled egress) and staff trained in dementia care. However, the staffing level for $A L / R C$ and $M C$ is the same (e.g., sufficient to meet resident needs), as are care planning and admission/discharge requirements. Our findings about license type suggest that residential mix may also be associated with regulatory deficiencies. Although we do not explicitly examine residentlevel data in this study, we can infer information about resident profiles based on license type. Specifically, prior research suggest that $\mathrm{MC}$ residents receive assistance with more activities of daily living compared to $\mathrm{AL}$ or $\mathrm{RC}$ residents, and a larger percentage of $R C$ residents have a diagnosed serious mental illness (SMI), compared to $A L$ and MC residents (Carder et al., 2018). These or other observable differences between licensure classifications might sensitize surveyors' attention to specific deficit areas if, for example, they have experienced the need to apply more stringent criteria on behalf of vulnerable residents, such as those with dementia or SMI.

Institutional Knowledge. Institutional knowledge might account for the increased risk of regulatory deficiencies. For example, longer-employed administrators might have greater experience and knowledge of $\mathrm{AL} / \mathrm{RC}$ policies and practices as well as greater familiarity with their staff and residents. Longer tenure is associated with staff stability in nursing homes (Castle, 2001). It is possible that administrators of AL/RC communities that receive deficiency citations might leave employment, either voluntarily or not 
(Geletta \& Sparks, 2013). This mechanism is supported by our finding that future survey year is associated with lower odds of regulatory deficiencies. It may be that communities improve their quality of care over time because of increased institutional knowledge. Alternatively, communities may be becoming better at avoiding deficiency citations (i.e. "playing the game" or "teaching to the test").

Resource Availability. We found that non-profit and urban communities have fewer deficiency citations, suggesting that AL/RC settings with more resources may have greater ability to address and prevent deficiency citations. Non-profit communities may be able to invest more resources into their facilities than for-profit communities, which are beholden to stakeholder interests. Rural location was also statistically associated with increased citation deficiencies, possibly because rural communities may have less access to a qualified labor force compared to metropolitan communities. Both non-profit and rural communities may have more access to unique funding opportunities such as government grants.

Market Pressure. Finally, market pressure may influence the attention and effort that communities invest into facility quality. We found that higher market concentration was associated with lower numbers of deficiency citations. This suggests that increased market pressure for filling the beds may provide external motivation for communities to improve the quality of care provided. However, this type of market pressure may also be a challenge for some $A L / R C$, as this could create pressure to lower profit margins to unsustainable levels - although our results do not support that conclusion. Limitations of the Current Study 
This study has limitations that must be considered with study findings. First, this is a single state study, therefore findings from this study may not be generalizable to communities outside of Oregon. To date there has been no national data on regulatory compliance in AL/RC communities, and because of the paucity of research on AL/RC regulatory deficiencies, we believe this study contributes to the literature and provides proof of concept for other states to follow. Future research could utilize similar datasets in other states, building on this study as a template for how to leverage multiple waves of survey data. Second, measurement error may limit our study findings. Specifically, the administrator tenure variable, derived from public records, might not capture the exact date of transfer from one administrator to another, especially if the same management company was retained. Finally, our study is associational, not causal. We cannot say with certainty that the characteristics we identified were causes of survey deficiencies. This has certain implications for our study. First, we cannot rule out reverse causality. For instance, administrators that did not receive deficiency citations in previous surveys may be more likely to stay on their jobs (instead of longer-tenured administrators receiving lower number of citations). Second, it is possible that unmeasured factors simultaneously influenced our dependent and independent variables. For example, policy changes during the study period may influenced the risk of receiving a specific deficiency citation for certain types of communities. We addressed this by focusing only on policies that did not change during the study period. Future analyses could control for time to account for policy changes. Another example relates to community ownership. In our sample, we found that community ownership changed frequently over time; around $10 \%$ of owners changed in 3 years. However, due 
to data limitations we were unable to reliably examine this relationship. Future research could examine how ownership changes influence other organizational characteristics. Conclusion

This study underscores a potential role for utilizing survey deficiency citations in constructing measures of quality for the AL/RC sector and cautions for adjusting such measures of quality for resident mix and structural factors. Our findings also highlight the need for future research to empirically establish links between deficiency citations and resident outcomes. For example, how does deficiency data correlate with important outcomes such as residents' experiences of quality and potential elder abuse, personcenteredness, or aspects of care delivery, such as meals, assistance with personal care tasks, and oversight of medical conditions? Considering the potential for real-time availability of $A L / R C$ inspection results, informative value of deficiency citations data for differentiating across $\mathrm{AL} / \mathrm{RC}$, and their observed sensitivity to market characteristics such as competition, ensuring public access to these data may improve LTSS provided to $\mathrm{AL} / \mathrm{RC}$ consumers. 


\section{References}

Carder, P. C. (2017). State Regulatory Approaches for Dementia Care in Residential Care and Assisted Living. The Gerontologist, gnw197. https://doi.org/10.1093/geront/gnw197

Carder, P.C., Tunalilar, O., Elliott S., \& Dys, S., (2018). 2018 Resident and Community Characteristics Report: Portland, OR: Portland State University. Institute on Aging. Available at: https://www.pdx.edu/institute-onaging/sites/g/files/znldhr3046/files/2020-07/2018 CBC AnnualReport AL-RCMC.pdf

Castle, N. G. (2001). Administrator turnover and quality of care in nursing homes. The Gerontologist, 41(6), 757-767.

Castle, N. G., Wagner, L. M., Ferguson, J. C., \& Handler, S. M. (2010). Nursing Home Deficiency Citations for Safety. Journal of Aging \& Social Policy, 23(1), 34-57. https://doi.org/10.1080/08959420.2011.532011

Castle, N. G., \& Ferguson, J. C. (2010). What Is Nursing Home Quality and How Is It Measured? The Gerontologist, 50(4), 426-442.

Castle, N. (2011). Nursing home deficiency citations for abuse. Journal of Applied Gerontology, 30(6), 719-743. https://doi.org/10.1177/0733464810378262

Eckert, J.K., Carder, P.C., Morgan, L.A., Frankowski, A.C., Roth, E. (2009). Inside Assisted Living. Johns Hopkins University Press.

Frytak, J. R., Kane, R. A., Finch, M. D., Kane, R. L., \& Maude-Griffin, R. (2001). Outcome trajectories for assisted living and nursing facility residents in Oregon. Health Services Research, 36(1 Pt 1), 91. 
Geletta, S., \& Sparks, P. J. (2013). Administrator turnover and quality of care in nursing homes. Annals of Long Term Care, 21(6).

Government Accountability Office. (2018). Medicaid Assisted Living Services: Improved Federal Oversight of Beneficiary Health and Welfare Is Needed. (GAO Publication No. 18-179). Washington, D.C.: U.S. Government Printing Office. Government Accountability Office. (2019). Elder Abuse: Federal Requirements for Oversight in Nursing Homes and Assisted Living Facilities Differ. (GAO Publication No. 19-599). Washington, D.C.: U.S. Government Printing Office. Harris-Kojetin L, Sengupta M, Lendon JP, Rome V, Valverde R, Caffrey C. Long-term care providers and services users in the United States, 2015-2016. National Center for Health Statistics. Vital Health Stat 3(43). 2019. https://www.cdc.gov/nchs/data/series/sr 03/sr03 43-508.pdf

Hawes C, \& Phillips CD. (2007). Defining quality in assisted living: comparing apples, oranges, and broccoli. Gerontologist, 47, 40-50. https://doi.org/10.1093/geront/47.supplement 1.40

House Bill 3359, 79th Oregon Legislative Assembly, 2018 Reg. Sess. (Oregon, 2018). Available at https://olis.leg.state.or.us/liz/2017R1/Downloads/MeasureDocument/HB3359/Enr olled

Institute of Medicine (US) Committee on Improving Quality in Long-Term Care. Improving the Quality of Long-Term Care. Wunderlich GS, Kohler PO, editors. Washington (DC): National Academies Press (US); 2001. PMID: 25077221. 
June, J. W., Meng, H., Dobbs, D., \& Hyer, K. (2019). Using Deficiency Data to Measure Quality in Assisted Living Communities: A Florida Statewide Study. Journal of Aging \& Social Policy, 1-16. https://doi.org/10.1080/08959420.2018.1563471

Kane, R. A. (2001). Long-Term Care and a Good Quality of Life: Bringing Them Closer Together. The Gerontologist, 41(3), 293. https://doi.org/10.1093/geront/41.3.293

Li, Y., Harrington, C., Temkin-Greener, H., You, K., Cai, X., Cen, X., Mukamel, D. (2015). Deficiencies in care at nursing homes and racial/ethnic disparities across homes fell, 2006-11. Health Affairs, 34 (7), 1139-1146. https://doi.org/10.1377/hlthaff.2015.0094

Mueller, C. (2002). Quality Care in Nursing Homes: When the Resources Aren't There. Journal of the American Geriatrics Society, 50(8), 1458-1460. https://doi.org/10.1046/j.1532-5415.2002.50373.x

Mullan JT, Harrington C. Nursing Home Deficiencies in the United States: A Confirmatory Factor Analysis. Research on Aging. 2001;23(5):503-531. https://10.1177/0164027501235001

Phillips, L. R., \& Guo, G. (2011). Mistreatment in Assisted Living Facilities: Complaints, Substantiations, and Risk Factors. The Gerontologist, 51(3), 343-353. https://doi.org/10.1093/geront/gnq122

Pfeffer, J., \& Salancik, G. R. (2003). The external control of organizations: A resource dependence perspective: Stanford, CA: Stanford University Press.

Rabe-Hesketh, S., and A. Skrondal. 2012. Multilevel and Longitudinal Modeling Using Stata. 3rd ed. College Station, TX: Stata Press. 
Smith, L., Carder, P., Bucy, T., Winfree, J., Brazier, J. F., Kaskie, B., \& Thomas, K. S. (2021). Connecting policy to licensed assisted living communities, introducing health services regulatory analysis. Health Services Research, 1475-

6773.13616. https://doi.org/10.1111/1475-6773.13616

Zimmerman S, Sloane PD, Williams CS, et al. Dementia Care and Quality of Life in Assisted Living and Nursing Homes. The Gerontologist. 2005;45(suppl_1):133146. https://doi.org/10.1093/geront/45.suppl_1.133

Zimmerman, S., Sloane, P. D., \& Reed, D. (2014). Dementia Prevalence And Care In Assisted Living. Health Affairs, 33(4), 658-666.

https://doi.org/10.1377/hlthaff.2013.1255 
Tables/Figures

Table 1. Descriptive statistics of deficiency citations by year, 2008-2016

\begin{tabular}{|l|l|l|l|l|}
\hline Year & Number of visits & $\begin{array}{l}\text { Did not receive } \\
\text { any citations }\end{array}$ & $\begin{array}{l}\text { Received at least } \\
\text { one citation }\end{array}$ & $\begin{array}{l}\text { Number of } \\
\text { deficiency citations }\end{array}$ \\
\hline & $\mathrm{n}(\%)$ & $\mathrm{n}(\%)$ & $\mathrm{n}(\%)$ & Mean (SD) \\
\hline 2008 & $137(100 \%)$ & $9(6.6 \%)$ & $128(93.4 \%)$ & $7.2(5.6)$ \\
\hline 2009 & $198(100 \%)$ & $43(21.7 \%)$ & $155(78.3 \%)$ & $6.2(6.1)$ \\
\hline 2010 & $239(100 \%)$ & $68(28.5 \%)$ & $171(71.6 \%)$ & $3.8(4.2)$ \\
\hline 2011 & $201(100 \%)$ & $36(17.9 \%)$ & $165(82.1 \%)$ & $5.7(5.3)$ \\
\hline 2012 & $195(100 \%)$ & $43(22.1 \%)$ & $152(78.0 \%)$ & $4.8(4.7)$ \\
\hline 2013 & $238(100 \%)$ & $75(31.5 \%)$ & $163(68.5 \%)$ & $3.9(4.3)$ \\
\hline 2014 & $192(100 \%)$ & $26(13.5 \%)$ & $166(86.5 \%)$ & $6.9(5.0)$ \\
\hline 2015 & $209(100 \%)$ & $49(23.4 \%)$ & $160(76.6 \%)$ & $5.1(4.8)$ \\
\hline 2016 & $217(100 \%)$ & $37(17.1 \%)$ & $180(83.0 \%)$ & $4.7(4.2)$ \\
\hline Total & $1,826(100 \%)$ & $386(21.1 \%)$ & $1,440(78.9 \%)$ & $5.2(5.0)$ \\
\hline
\end{tabular}

Note: Data are from 1,826 initial and re-licensure survey visits from $526 \mathrm{AL} / \mathrm{RC}$ licensed in Oregon between 2008 and 2016. Mean was calculated as the average number of deficiency citations per survey visit, including those that did not result in any citations. $n$ = number; $\%$ = percentage; $\mathrm{SD}=$ standard deviation. 
Table 2. AL/RC characteristics at survey year by whether survey resulted in deficiency citations

\begin{tabular}{|c|c|c|c|}
\hline Variable & $\begin{array}{l}\text { No citation } \\
(n=386 ; \\
21.1 \%)\end{array}$ & $\begin{array}{l}\text { One or more } \\
\text { citations } \\
(n=1,440 ; \\
78.9 \%)\end{array}$ & $\begin{array}{l}\text { All visits } \\
(n=1,826 \\
100 \%)\end{array}$ \\
\hline \multicolumn{4}{|l|}{ Organizational Characteristics } \\
\hline Survey year $(\mathrm{M})$ & $2012.2(2.3)$ & $2012.1(2.6)$ & $2012.2(2.5)$ \\
\hline $\begin{array}{l}\text { Years open at the time of survey } \\
\text { (M) }\end{array}$ & $13.1(7.0)$ & $13.8(8.1)$ & $13.7(7.9)$ \\
\hline \multicolumn{4}{|l|}{ Size* } \\
\hline $6-24$ & $37.6 \%$ & $21.7 \%$ & $25.0 \%$ \\
\hline $25-49$ & $26.4 \%$ & $27.0 \%$ & $26.9 \%$ \\
\hline $50-74$ & $20.0 \%$ & $28.3 \%$ & $26.6 \%$ \\
\hline $75-99$ & $13.2 \%$ & $16.3 \%$ & $15.7 \%$ \\
\hline 100 and over & $2.9 \%$ & $6.7 \%$ & $5.9 \%$ \\
\hline \multicolumn{4}{|l|}{ License Type* } \\
\hline $\mathrm{AL}$ & $41.7 \%$ & $46.2 \%$ & $45.2 \%$ \\
\hline $\mathrm{RC}$ & $36.5 \%$ & $25.4 \%$ & $27.7 \%$ \\
\hline MC & $19.7 \%$ & $21.9 \%$ & $21.5 \%$ \\
\hline Mixed & $2.1 \%$ & $6.5 \%$ & $5.6 \%$ \\
\hline Medicaid contract* & $71.0 \%$ & $79.8 \%$ & $77.9 \%$ \\
\hline Administrator tenure (in years) $(\mathrm{M})^{*}$ & $2.9(2.5)$ & $2.4(2.4)$ & $2.5(2.5)$ \\
\hline Non-profit* & $14.8 \%$ & $9.5 \%$ & $10.6 \%$ \\
\hline Highest quartile of market share* & $18.7 \%$ & $26.7 \%$ & $25.0 \%$ \\
\hline \multicolumn{4}{|l|}{ Environment Characteristics } \\
\hline \multicolumn{4}{|l|}{ CBSA Code } \\
\hline Metropolitan & $80.3 \%$ & $76.8 \%$ & $77.6 \%$ \\
\hline Rural & $2.9 \%$ & $4.9 \%$ & $4.5 \%$ \\
\hline Micropolitan & $16.8 \%$ & $18.3 \%$ & $18.0 \%$ \\
\hline Number of SNF beds in county (M) & $907.4(869.4)$ & $916.2(907.2)$ & $914.3(899.1)$ \\
\hline \multicolumn{4}{|l|}{$\begin{array}{l}\text { Highest quartile of percent of } \\
\text { population who are: }\end{array}$} \\
\hline Older adults & $27.2 \%$ & $24.2 \%$ & $24.9 \%$ \\
\hline In poverty & $26.2 \%$ & $22.2 \%$ & $23.0 \%$ \\
\hline Unemployed* & $28.5 \%$ & $23.0 \%$ & $24.2 \%$ \\
\hline Dual Medicaid/Medicare eligible & $22.8 \%$ & $25.3 \%$ & $24.8 \%$ \\
\hline \multicolumn{4}{|l|}{$\mathrm{HHI}$} \\
\hline Most competitive (0.03-0.05) & $33.4 \%$ & $33.7 \%$ & $33.6 \%$ \\
\hline $\begin{array}{l}\text { Moderately concentrated }(0.06 \text { - } \\
0.22 \text { ) }\end{array}$ & $37.6 \%$ & $32.2 \%$ & $33.4 \%$ \\
\hline Highly concentrated $(0.23-1.00)$ & $29.0 \%$ & $34.1 \%$ & $33.0 \%$ \\
\hline
\end{tabular}


different at $p<0.05$ in bivariate analyses between facilities with no deficiency citations versus one or more deficiency citations based on $t$-tests (means) and Pearson's chisquared (percentages). $A L=$ assisted living; $R C=$ residential care; $M C=$ memory care . 
Figure 1. Prevalence of a Subset of Deficiency Citations for Licensing Visits

\section{Description of Tags}

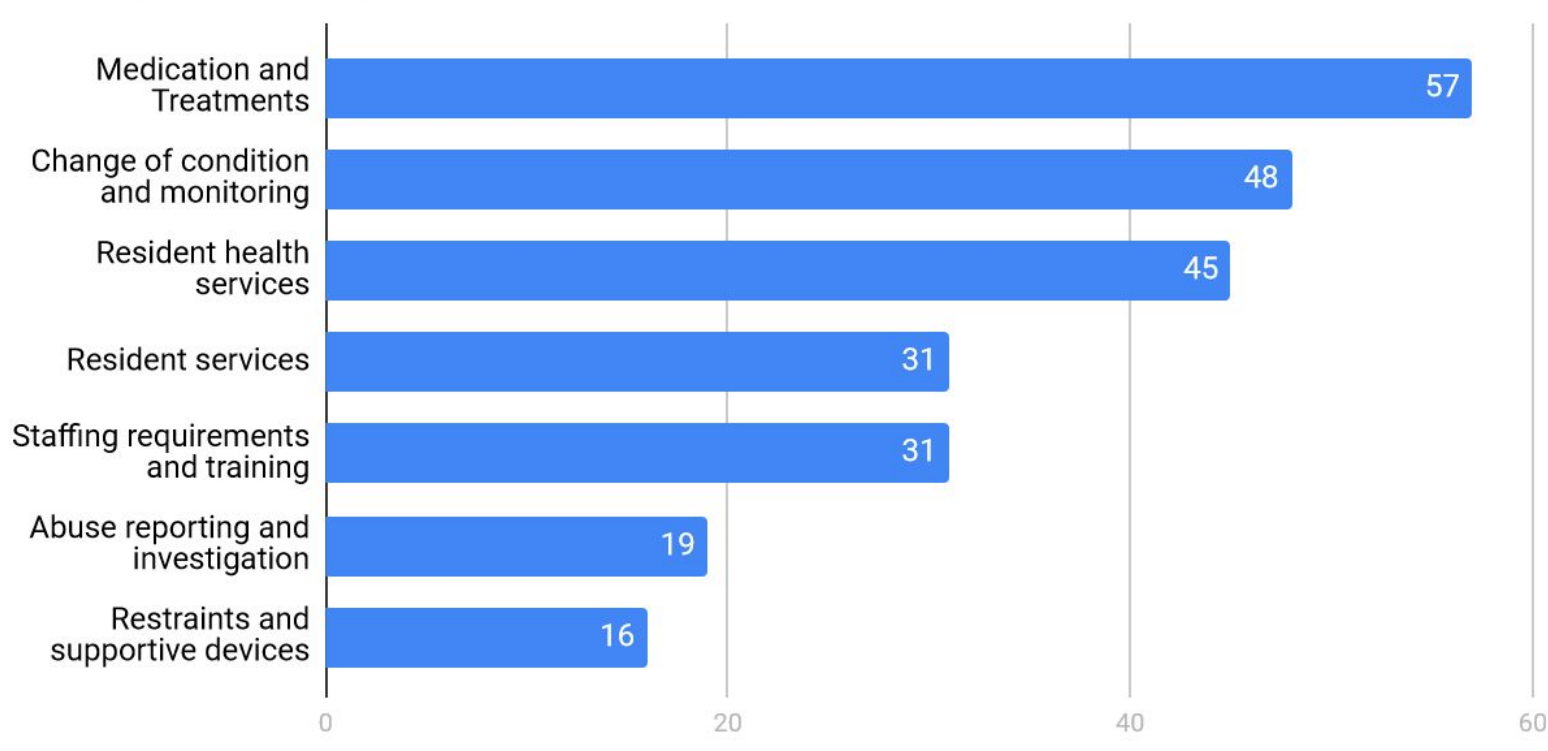

Percent of Visits

Note: Percentages based on 1,826 initial and re-licensure survey visits from $527 \mathrm{AL} / \mathrm{RC}$ licensed in Oregon between 2008 and 2016. Survey visits that resulted in a specific tag more than once during a visit are included only once. 
Supplemental Tables

Supplemental Table 1. Sensitivity Analysis Dropping 2008-2009 Data

\begin{tabular}{|c|c|c|c|c|}
\hline & $\begin{array}{l}\text { Logit } \\
\text { OR/IRR }\end{array}$ & $95 \%$ CI & $\begin{array}{r}\text { Poisson } \\
\text { OR/IRR }\end{array}$ & $95 \%$ CI \\
\hline Survey year & 1.07 & {$[0.97,1.17]$} & 1.01 & {$[0.99,1.04]$} \\
\hline $\begin{array}{l}\text { \# years open at time of survey } \\
\text { Size (ref. } 6-24)\end{array}$ & \multicolumn{3}{|c|}{ Size (ref. 6-24) } & {$[0.99,1.01]$} \\
\hline $25-49$ & $2.13 * *$ & {$[1.33,3.42]$} & $1.76 * * *$ & {$[1.42,2.17]$} \\
\hline $50-74$ & $2.96 * * *$ & {$[1.65,5.33]$} & $1.89 * * *$ & {$[1.49,2.39]$} \\
\hline $75-99$ & $2.47 * *$ & {$[1.27,4.83]$} & $1.96 * * *$ & {$[1.50,2.57]$} \\
\hline 100 and over & $7.15 * * *$ & {$[2.80,18.24]$} & $2.74 * * *$ & {$[2.08,3.62]$} \\
\hline \multicolumn{5}{|l|}{ License Type (ref. AL) } \\
\hline $\mathrm{RC}$ & 1.10 & {$[0.67,1.80]$} & $1.41 * * *$ & {$[1.16,1.71]$} \\
\hline MC & $1.78 *$ & {$[1.09,2.90]$} & $1.38 * * *$ & {$[1.16,1.65]$} \\
\hline Mixed & $2.86^{*}$ & {$[1.28,6.37]$} & $1.51 * * *$ & {$[1.21,1.87]$} \\
\hline Medicaid & 1.30 & {$[0.89,1.88]$} & 1.13 & {$[0.95,1.34]$} \\
\hline Admin. Tenure & $0.93 *$ & {$[0.87,0.99]$} & $0.97 *$ & {$[0.95,1.00]$} \\
\hline Nonprofit (ref. For-Profit) & $0.45 * *$ & {$[0.26,0.76]$} & $0.61 * * *$ & {$[0.47,0.79]$} \\
\hline Highest quartile of market share & 1.35 & {$[0.75,2.43]$} & 1.20 & {$[0.92,1.55]$} \\
\hline \multicolumn{5}{|l|}{ CBSA Code (ref. Metropolitan) } \\
\hline Rural & $3.20 *$ & {$[1.15,8.88]$} & $2.01 * * *$ & {$[1.42,2.84]$} \\
\hline Micropolitan & 1.05 & {$[0.57,1.93]$} & 0.96 & {$[0.74,1.23]$} \\
\hline Number of SNF beds in county & 1.00 & {$[1.00,1.00]$} & 1.00 & {$[1.00,1.00]$} \\
\hline Highest quartile of percent of $p$ & 0.76 & {$[0.50,1.16]$} & 0.85 & {$[0.70,1.02]$} \\
\hline Highest quartile of percent of $p$ & 0.88 & {$[0.60,1.29]$} & 1.04 & {$[0.88,1.22]$} \\
\hline Highest quartile of percent unem & 1.01 & {$[0.65,1.58]$} & $0.82 *$ & {$[0.68,0.99]$} \\
\hline Highest quartile of percent of $p$ & 1.35 & {$[0.81,2.25]$} & 1.06 & {$[0.88,1.27]$} \\
\hline \multicolumn{5}{|l|}{ HHI (ref. Most competitive) } \\
\hline Moderate Concentrated & 0.74 & {$[0.45,1.23]$} & 0.97 & {$[0.78,1.19]$} \\
\hline Highly Concentrated & 1.15 & {$[0.53,2.47]$} & 1.22 & {$[0.86,1.71]$} \\
\hline
\end{tabular}


Supplemental Table 2. Sensitivity Analysis Using Mixed-Effects Negative Binomial Model

\begin{tabular}{|c|c|c|}
\hline & $\begin{array}{r}\text { Nbreg } \\
\text { OR/IRR }\end{array}$ & $95 \% \mathrm{CI}$ \\
\hline Survey year & $0.96 * * *$ & {$[0.95,0.98]$} \\
\hline $\begin{array}{l}\text { \# years open at time of survey } \\
\text { Size (ref. 6-24) }\end{array}$ & 1.01 & {$[1.00,1.01]$} \\
\hline $25-49$ & $1.47 * * *$ & {$[1.24,1.75]$} \\
\hline $50-74$ & $1.70 * * *$ & {$[1.40,2.07]$} \\
\hline $75-99$ & $1.69 * * *$ & {$[1.35,2.12]$} \\
\hline 100 and over & $2.31 * * *$ & {$[1.80,2.97]$} \\
\hline \multicolumn{3}{|l|}{ License Type (ref. AL) } \\
\hline $\mathrm{RC}$ & $1.37 * * *$ & {$[1.16,1.61]$} \\
\hline MC & $1.27^{* *}$ & {$[1.09,1.47]$} \\
\hline Mixed & $1.44 * * *$ & {$[1.21,1.71]$} \\
\hline Medicaid & $1.23 * *$ & {$[1.08,1.41]$} \\
\hline Admin. Tenure & $0.97 * *$ & {$[0.95,0.99]$} \\
\hline Nonprofit (ref. For-Profit) & $0.66 * * *$ & {$[0.54,0.82]$} \\
\hline Highest quartile of market share & 1.08 & {$[0.87,1.33]$} \\
\hline \multicolumn{3}{|l|}{ CBSA Code (ref. Metropolitan) } \\
\hline Rural & $2.01 * * *$ & {$[1.49,2.70]$} \\
\hline Micropolitan & 1.03 & {$[0.84,1.26]$} \\
\hline Number of SNF beds in county & 1.00 & {$[1.00,1.00]$} \\
\hline Highest quartile of percent of $p$ & 0.87 & {$[0.74,1.02]$} \\
\hline Highest quartile of percent of $p$ & 0.89 & {$[0.79,1.00]$} \\
\hline Highest quartile of percent unem & $0.82 * *$ & {$[0.72,0.93]$} \\
\hline Highest quartile of percent of $p$ & 1.09 & {$[0.94,1.27]$} \\
\hline \multicolumn{3}{|l|}{ HHI (ref. Most competitive) } \\
\hline Moderate Concentrated & $1.25 * *$ & {$[1.07,1.45]$} \\
\hline Highly Concentrated & $1.31 *$ & {$[1.01,1.69]$} \\
\hline lnalpha & $0.82 * *$ & {$[0.70,0.95]$} \\
\hline
\end{tabular}


Supplemental Table 3. Sensitivity Analysis Dropping Number of Certified SNF Beds in County as a Covariate

\begin{tabular}{|c|c|c|c|c|}
\hline & Logit & & Poisson & \\
\hline & OR/IRR & $95 \%$ CI & OR/IRR & $95 \% \mathrm{CI}$ \\
\hline Survey year & $0.93 *$ & {$[0.88,0.98]$} & $0.96 * * *$ & {$[0.94,0.98]$} \\
\hline $\begin{array}{l}\text { \# years open at time of survey } \\
\text { Size (ref. 6-24) }\end{array}$ & 1.01 & {$[0.99,1.03]$} & 1.01 & {$[1.00,1.02]$} \\
\hline $25-49$ & $1.92 * *$ & {$[1.25,2.93]$} & $1.40 * * *$ & {$[1.15,1.70]$} \\
\hline $50-74$ & $2.77 * * *$ & {$[1.63,4.70]$} & $1.61 * * *$ & {$[1.28,2.03]$} \\
\hline 75-99 & $2.44 * *$ & {$[1.34,4.45]$} & $1.68 * * *$ & {$[1.29,2.18]$} \\
\hline 100 and over & $5.03 * * *$ & {$[2.24,11.29]$} & $2.45 * * *$ & {$[1.82,3.29]$} \\
\hline License Type (ref. AL) & & & & \\
\hline $\mathrm{RC}$ & 1.09 & {$[0.70,1.70]$} & $1.32 * *$ & {$[1.11,1.58]$} \\
\hline MC & $1.83 * *$ & {$[1.17,2.85]$} & $1.35 * * *$ & {$[1.14,1.59]$} \\
\hline Mixed & $3.15 * *$ & {$[1.47,6.78]$} & $1.46 * * *$ & {$[1.20,1.77]$} \\
\hline Medicaid & 1.31 & {$[0.93,1.85]$} & 1.12 & {$[0.95,1.32]$} \\
\hline Admin. Tenure & $0.92 * *$ & {$[0.87,0.98]$} & $0.97 *$ & {$[0.95,1.00]$} \\
\hline Nonprofit (ref. For-Profit) & $0.47^{* *}$ & {$[0.29,0.76]$} & $0.60 * * *$ & {$[0.46,0.77]$} \\
\hline Highest quartile of market share & 1.24 & {$[0.71,2.19]$} & 1.20 & {$[0.95,1.51]$} \\
\hline CBSA Code (ref. Metropolitan) & & & & \\
\hline Rural & $3.01 *$ & {$[1.14,7.99]$} & $1.80 * * *$ & {$[1.28,2.53]$} \\
\hline Micropolitan & 1.01 & {$[0.57,1.77]$} & 0.92 & {$[0.71,1.19]$} \\
\hline Highest quartile of percent of $p$ & 0.79 & {$[0.53,1.18]$} & 0.92 & {$[0.77,1.10]$} \\
\hline Highest quartile of percent of $p$ & 0.76 & {$[0.54,1.08]$} & 0.91 & {$[0.80,1.03]$} \\
\hline Highest quartile of percent unem & $0.64 * *$ & {$[0.47,0.89]$} & $0.83 * *$ & {$[0.72,0.94]$} \\
\hline Highest quartile of percent of $p$ & 1.25 & {$[0.86,1.81]$} & 1.05 & {$[0.89,1.23]$} \\
\hline HHI (ref. Most competitive) & & & & \\
\hline Moderate Concentrated & 0.92 & {$[0.62,1.34]$} & 1.15 & {$[0.97,1.35]$} \\
\hline Highly Concentrated & 1.43 & {$[0.77,2.67]$} & $1.35 *$ & {$[1.02,1.79]$} \\
\hline
\end{tabular}

